\title{
Think Mobile: The Experience of a University towards more Complex Services
}

\author{
Christian Cousquer $^{1}$ \\ ${ }^{1}$ University Pierre \& Marie Curie-Sorbonne Universités, S.G.Tice/CPM, 4 place Jussieu, 75252 Paris \\ Cedex 05, christian.cousquer@upmc.fr
}

Keywords

Mobile, desktop, frontend, portal, Apereo, uPortal, uMobile, html5, css3, JavaScript.

\section{ABSTRACT}

Among adaptations of existing services, progressive enhancements, (perceived) performances, Mobile First or MultiTouch First and Responsive Design conceptions, without any dogmatism, this is an unpretentious attempt to think Mobile and Desktop at University Pierre \& Marie Curie-Sorbonne Universités - viewed from the Front-End side - through three examples of deployment: a new version of an existing Portal solution -uPortal/uMobile 4-, the University Pierre \& Marie Curie on iTunes U site and a home made Video Library and their Video Capture Workflow.

I will focus on the Context, the Web Context, the historical adoption of software, the Institution, sometimes all this looks like a fine mess, but strangely and with reactivity, things may be done progressively, I will talk about concepts and issues we've encountered at the University Pierre \& Marie Curie.

There is a French expression «Diable se cache dans les details » literally: "The devil lurks in the details"- in English, the same expression is "Success lies in the details", so strange, isn't it?

\section{PAPER}

In today's incredibly exciting yet overwhelming world of connected digital devices and computers, the diversity of connected devices - many of which we haven't imagined yet - is exploding, as will the quantity and diversity of the practices.

Our existing standards, developing practices, workflows, and infrastructure have quite already been pushed to a breaking point. Some of them may perhaps not withstand what's ahead.
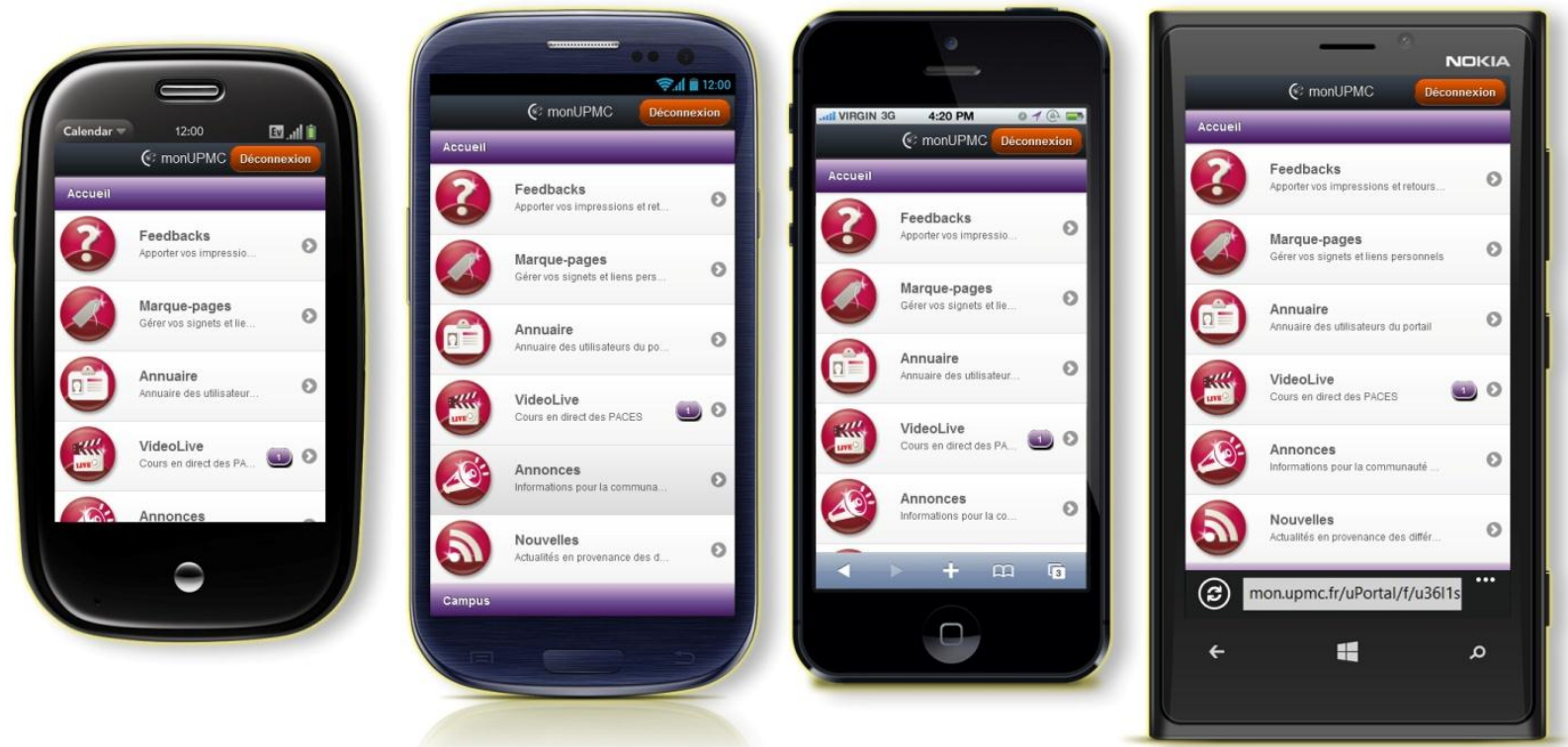

Figure 1. An Authenticated Student's Mobile View on the Portal: https://mon.upmc.fr 
Innovation necessarily precedes standardization and standards process and adoption are sometimes painfully slow. We are struggling with (and eventually agreeing to) appropriate standards, frameworks, tools and methods, learning or improving new languages. In this period, where the web seems to fall even further behind proprietary solutions, how can we be neutral in a public institution?

Among adaptations of existing services, progressive / adaptive enhancements, (perceived) performance, responsive design and Mobile First conception, without any dogmatism, this is an unpretentious attempt to think Mobile and Desktop at University Pierre \& Marie Curie-Sorbonne Universités - viewed from the Front-End side - through three examples of deployment: a new version of an existing Portal solution, the University Pierre \& Marie Curie on iTunes $U$ site and a home made Video Library and their Video Capture Workflow.

All this is related to technology, computer programs and software constantly changing. It also implies that for men and organizations must think, improve, renew their own practices, ensure a constant technology watch, and develop their programs and deployments in simple tasks -even atomic- and scalable; not to mention how to share, communicate, coordinate and the management that it entails, also evolving constantly.

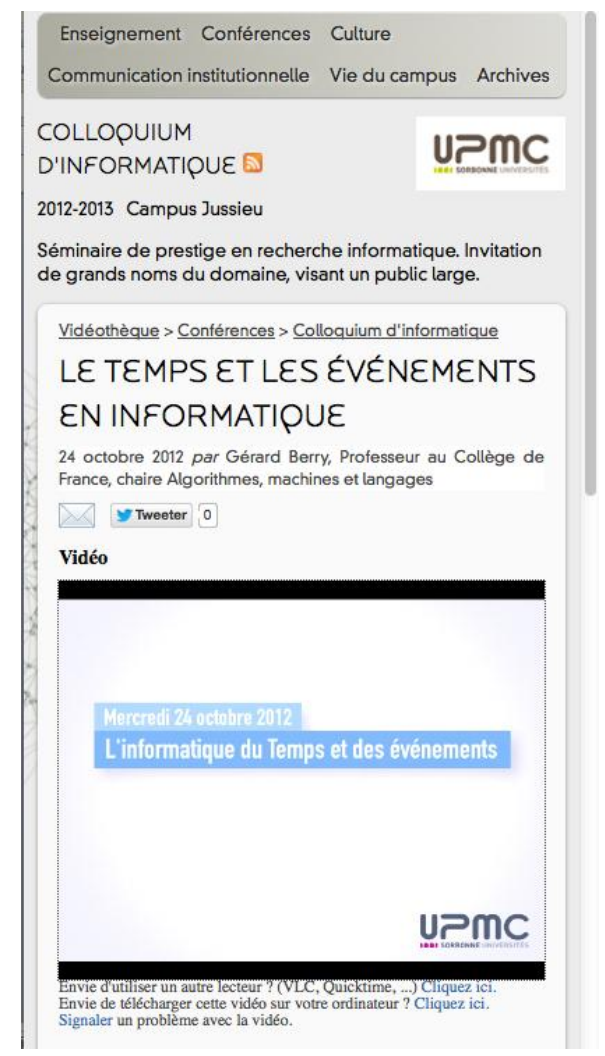

Figure 1. Mobile Web View of a Colloquium in the Video Library: http://video.upmc.fr

This is related also with the Context, the Web Context, the historical adoption of software, the Institution, the background of the people, sometimes all this looks like a fine mess, but strangely and with reactivity, things may be done progressively.

There is a French expression « le Diable se cache dans les détails »-literally: "The devil lurks in the details"- in English, the same expression is "Success lies in the details", so strange, isn't it? 


\section{REFERENCES}

UPMC's Portal. Location: https://mon.upmc.fr

UPMC's Video Library. Location: http://video.upmc.fr

UPMC's iTunes U Site. Location: http: //itunes.upmc.fr

David Bushell. Implementing Off-Canvas Navigation For A Responsive Website. Location: http://coding.smashingmagazine.com/2013/01/15/off-canvas-navigation-for-responsive-website/

Brad Frost. This is responsive. Location: http://bradfrost.github.io/this-is-responsive/

Addy Osmani. Articles for developers. Rauschmayer. 2ality - JavaScript and more. Location: http://addyosmani.com/blog/

Mozilla Developer Network, Location: https://developer.mozilla.org/en/ Any copyright is dedicated to the Public Domain

Dr. Axel Rauschmayer. 2ality - JavaScript and more. Location: http://www.2ality.com.

Tali Garsiel \& Paul Irish. Aug. 5, 2011, How Browsers Work: Behind the scenes of modern web

browsers. Location: http://www.html5rocks.com/en/tutorials/internals/howbrowserswork/

\section{AUTHORS' BIOGRAPHIES}

\section{Christian Cousquer.}

Ingénieur en développement et déploiement d'applications - Université Pierre et Marie Curie Sorbonne Université. 